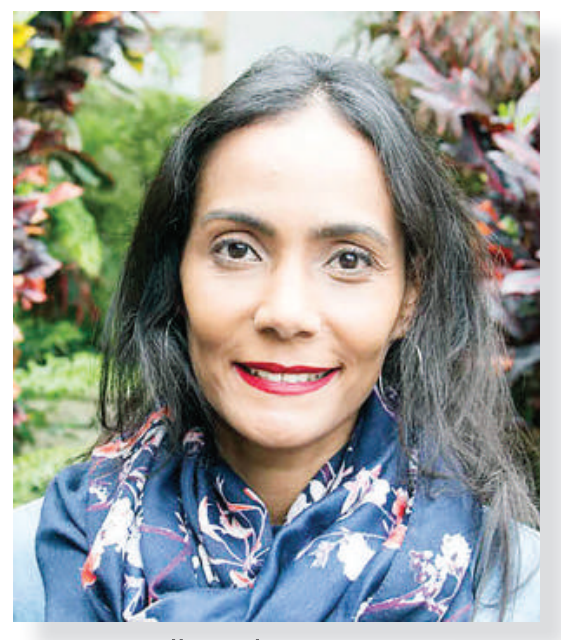

Orisell Medina Lagrange*

\section{Estrategias de proyectos que fomentan la conciencia medioambiental y el bien común: Intervenciones de la arquitectura en el paisaje}

\section{Architectural interventions in the environment: Teaching and learning strategies that develop students' environmental awareness}

Recibido: 03-05-18

Aprobado: 13-06-18

\title{
Resumen
}

Esta investigación presenta las estrategias que facilitaron que los estudiantes de arquitectura desarrollaran un aprendizaje interdisciplinario, activo y experiencial al trabajar en proyectos de paisaje con medios vivos. Los aportes alcanzados dieron cuenta del inicio de una comprensión más directa y consciente sobre el medioambiente y el bien común, al vivenciar los aportes que esta visión puede ofrecer a la calidad de vida del ser humano y a la salvaguarda de la naturaleza en la ciudad. Este estudio descriptivo y aplicado busca referir los procesos de la interacción didáctica y la interpretación de los mismos con el fin de aportar elementos de reflexión sobre la práctica educativa. El diseño de esta investigación transversal partió del análisis de las respuestas obtenidas mediante cuestionarios online sobre el impacto de las estrategias utilizadas durante el transcurso de tres periodos académicos y tres grupos de estudiantes en la asignatura Arquitectura y Paisaje de la Escuela de Arquitectura de la Pontificia Universidad Católica Madre y Maestra, Campus Santo Tomás de Aquino. Los resultados principales muestran la preferencia de los estudiantes al desarrollo de proyectos de espacios verdes colectivos y el aumento de la noción del impacto en el medioambiente para la toma de decisiones en el proceso de diseño.

\section{Abstract}

This article presents the strategies that allowed a group of architecture students to develop experiential, active learning, and interdisciplinary skills while working landscaping projects. Findings suggest greater levels of student environmental awareness and a more honed conscience regarding their relationship with the natural environment and the idea of a common good. In an attempt to provide an in-depth reflection about the educational process, this descriptive and applied study refers the processes of didactic interaction and their interpretations The design of this cross-sectional research uses data obtained through an online survey on the impact of the strategies used throughout three academic periods and three student groups in the Architecture and Landscape course taken at Pontificia Universidad Católica Madre y Maestra's School of Architecture. Results witness students prefer the development of projects in green, open and collective spaces, as well as an increase in the study of their impact on the environment in the design phase of their projects.

\section{Palabras clave}

proyectos; conciencia medioambiental; paisaje; entorno natural

\section{Keywords}

projects; environmental awareness; landscape; natural environment

\footnotetext{
*Arq. Orisell Medina Lagrange: Candidata a PhD en Arquitectura y Urbanismo en la Universidad del Bío Bío, Chile, con un marcado interés en los procesos de investigación e innovación educativa. Profesora a tiempo completo de la Escuela de Arquitectura y Diseño en la Facultad de Ciencias Sociales, Humanidades y Artes de la Pontificia Universidad Católica Madre y Maestra. Para contactar a la autora: orisellmedina@pucmm.edu.do
} 


\section{Introducción}

La asignatura de Arquitectura y Paisaje ARQ-444-T ha sido abordada de manera independiente por cada profesor que la ha impartido siguiendo pautas desde el programa, lo que ha dado como resultado que cada profesor haya ido construyendo su visión de la materia.

Desde el aula se constató la necesidad de reforzar y dar un giro al enfoque a través del cual se impartían los contenidos con el fin de cambiarlos por otros más aplicables a los problemas ambientales del mundo de hoy, puesto que en muchos casos era evidente que mayormente primaba la idea de que lo que podía generarse como conocimiento desde la asignatura era exclusivamente la vertiente estética del uso de plantas y cómo incorporarlas en el proyecto, lo que dio pie a descubrir la escasa conexión en el proceso de aprendizaje de los estudiantes entre el entorno natural y su integración con lo construido y el cuidado del medioambiente en esta ecuación.

Es en este marco que se inicia la indagación de nuevos modos de accionar en la enseñanza-aprendizaje de la Arquitectura y Paisaje, los cuales permitieron al estudiante comprender la conexión de los procesos del entorno natural y sus condicionantes con nuevas formas de pensamiento sobre la inserción de la naturaleza en el diario vivir del ser humano y su entorno construido desde lo actual y conectado a corrientes de acción globales.

En diferentes períodos se fueron incorporando diversos proyectos de diseño hasta llegar a algunas actuaciones para la construcción del paisaje, pero a pesar de estos intentos, no existía una forma sistematizada de impartir la asignatura, por lo cual, fueron haciéndose cambios graduales en cuanto a las temáticas de los proyectos en los años 2008-2009-2010. En el 2012 y 2013 se hace un giro y se comienza a incursionar en proyectos como el denominado "Paisaje de Calle" o StreetScape, donde se plantearon propuestas de hacer coincidir el bienestar humano unido a la inserción de la naturaleza en los espacios públicos de la ciudad.

Pero, a pesar de esos cambios y luego de un tiempo de receso de tres años de no impartir la asignatura Arquitectura y Paisaje, en el 2016 se incorporan nuevas estrategias al desarrollo del curso y nuevas visiones al conectar con las iniciativas mundiales del PARK(ing) Day auspiciado por la organización Rebar y Guerrilla Gardening. Esta necesidad de cambio y mejora constante del proceso de enseñanza-aprendizaje viene de la mano de las experiencias desarrolladas a partir de las formaciones profesionalizantes en pedagogía dentro de la PUCMM, donde se tuvo la oportunidad de repensar las estrategias para gestar los cambios necesarios que promovieran un mejor proceso de enseñanza-aprendizaje (E-A).

Este estudio se propone determinar en qué medida el uso de estrategias de aprendizaje enmarcadas en redes globales de colaboración y de construcción de proyectos efímeros de paisaje contribuyen a lograr el pensamiento crítico, creativo y solucionador de problemas en el proceso de E-A. Para lograr este cambio, no solo en la asignatura, sino lo que es más importante, en la visión y sensibilidad medioambiental de los estudiantes, fue necesario indagar sobre distintos proyectos efímeros que integran el medioambiente para escoger los más idóneos de acuerdo al objetivo trazado, e implementar nuevas estrategias que apuntaran al trabajo orientado a proyectos y al trabajo en equipo.

Este artículo aporta un contenido relevante para los docentes que imparten asignaturas prácticas y creativas, dada la necesidad de implementar un aprendizaje activo y solucionador de problemas, y más cuando se trata de desarrollar una conciencia adecuada hacia el medioambiente y el bien común. Iniciaremos con una fundamentación sobre la enseñanza de la arquitectura y el paisaje y las mejores estrategias para lograr un aprendizaje vivencial y competente; luego, presentamos las actividades implementadas detallando cada estrategia que utilizamos a lo largo de tres cuatrimestres; en tercer lugar, presentamos los resultados del impacto de las estrategias y retos vividos por los estudiantes a través de encuestas online. Finalmente, exponemos las conclusiones a las que ha llegado el estudio.

\section{Fundamentación}

\section{La enseñanza de la Arquitectura y Paisaje.}

La enseñanza del paisaje y su incursión dentro de la disciplina de la Arquitectura tiende a facilitar que los estudiantes conozcan otros medios para comprender e intervenir el entorno donde se construye la arquitectura. Es preciso clarificar que la Arquitectura del Paisaje como tal es una carrera independiente de la Arquitectura, con la misma duración en años académicos y que en los últimos decenios ha tomado un auge importante, llegando a ser los arquitectos paisajistas muchas veces los líderes de equipos multidisciplinares de proyectos. En ese contexto es sustancial recordar que, si la Arquitectura tiene que ver con los espacios construidos por el hombre para habitar, el paisaje definido por Alexander von Humboldt en Erminsher (2011, p. 394) es "la totalidad de los aspectos de una región"; es entonces que la diferencia entre Arquitectura y Arquitectura del Paisaje se plasman en los medios, las técnicas y los materiales (Laurie, 1983). 
Es por esto que las características de esta disciplina según Gazvoda (2002, p. 117) requiere de quienes sean profesionales de ella estén "familiarizados con un amplio rango de conocimientos del campo de las ciencias naturales y creatividad artística a la vez". Bajo este escenario es donde converge la inclusión de la asignatura de Arquitectura y Paisaje ARQ-444-T en la carrera de Arquitectura, en la cual los estudiantes comienzan a comprender esa diversidad de medios a través de los cuales opera la Arquitectura del Paisaje.

Para Filor (1994), el proceso del diseño de paisaje es definido como "reflexión en acción" (usando el concepto de Schön, 1985), pues el diseñador debe evaluar los requerimientos de un diseño particular vs. la capacidad del lugar, para asegurar que el impacto de los cambios producidos en el medioambiente sea mínimo.

Es así que en la enseñanza del paisaje converge lo que Martínez de Pisón (2012, p. 374) denomina como rostros, "estructuras espaciales, geográficas, naturales, históricas, ecológicas, económicas, sociales y culturales", llegando a suceder prácticas medioambientalmente contraproducentes, o ejercidas bajo visiones que son perjudiciales para el paisaje.

Siendo la naturaleza la materia prima y asiento de la Arquitectura del Paisaje, es perentorio tener una comprensión consciente de los procesos de la misma y de la interacción del ser humano con ella. El término conciencia ambiental se refiere según Gomera $(2008$, p. 2) al "sistema de vivencia, conocimientos y experiencias que el individuo utiliza activamente en su relación con el medioambiente, y es un concepto multidimensional: cognitivo, afectivo, conativo y activo"; alcanzar un grado adecuado de conciencia ambiental implica desarrollar niveles mínimos de esas dimensiones:

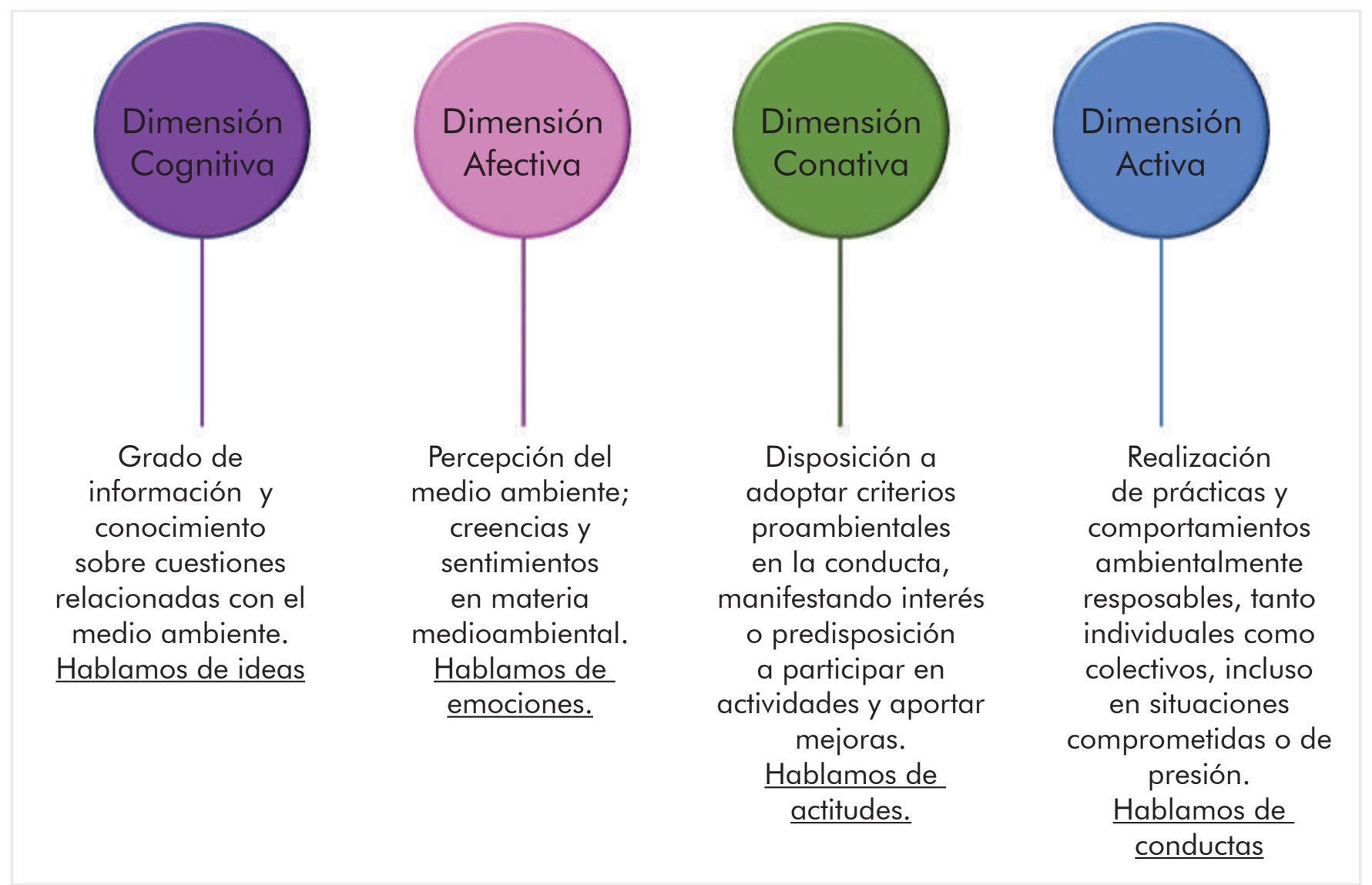

Figura 1: Dimensiones de la conciencia ambiental. Elaboración a partir de Gomera (2008).

Esto lleva a comprender la pertinencia de abocarse a indagar en diversas estrategias de E-A que permitan un trabajo consciente con el medio ambiente, parte fundamental del proyecto de paisaje.

\section{Estrategias de enseñanza-Aprendizaje en Arquitectura y Paisaje.}

"Dime y lo olvido, enséñame y lo recuerdo, involúcrame y lo aprendo". 
El aprendizaje orientado a proyectos en la enseñanza de la Arquitectura constituye un reto para docentes y estudiantes, dada la gran carga de subjetividad que se involucra en este ámbito, desde la misma ideación del problema a resolver hasta el proceso de resolución en sí mismo. Es preciso entonces integrar el saber en el hacer, de una manera estructurada a través de las estrategias, definidas por Medina (2011) como la forma en que se realiza una acción determinada con el fin de obtener un resultado particular.

En el ámbito educativo se definen las estrategias de enseñanza-aprendizaje como los procedimientos que el docente utiliza de forma reflexiva y flexible para promover el logro de aprendizajes significativos en los estudiantes (Díaz-Barriga y Hernández,1999). Estos autores indican que el docente debe tomar en cuenta los siguientes aspectos en la selección de las estrategias:

- Considerar las características generales de los aprendices (nivel de desarrollo cognitivo, conocimientos previos, motivación, etc.).

- Tipo de dominio del conocimiento general y del contenido curricular particular a abordar.

- Los objetivos que se plantean obtener y las actividades cognitivas que el aprendiz realizará para aprender.

- Tener conocimiento pleno y constante del proceso de enseñanza y del progreso y aprendizaje de los estudiantes.

- Determinar el contexto de significados compartidos y construidos creado con los estudiantes.

Lo descrito implica definir la intencionalidad de las estrategias a utilizar. Para Raths, en Zabalza (2003), los criterios a tomar en cuenta al definir y decidir cuáles estrategias programar en el proceso de enseñanza-aprendizaje vienen dados por el nivel de gratificación de una u otra, al hacer que los estudiantes asuman un papel activo, que las actividades ideadas por el docente involucren la realización de actividades reflexivas, la interacción con objetos, resolución de problemas, aplicación de nuevas perspectivas a problemas ya estudiados, que se posibilite el correr riesgos, entre otras.

En otro ámbito, Kolb (1984) aporta sobre los medios que facilitan el aprendizaje a partir de la Teoría de Aprendizaje Experiencial, la cual plantea la importancia de la experiencia durante el proceso de aprendizaje. Para Gómez (2008) la teoría de Kolb al abordar los diversos estilos mediante los cuales las personas aprenden, explora las experiencias y cómo estas son conducidas. Este autor indica el proceso circular que parte de la experiencia concreta:

\section{EXPERIENCIA CONCRETA}
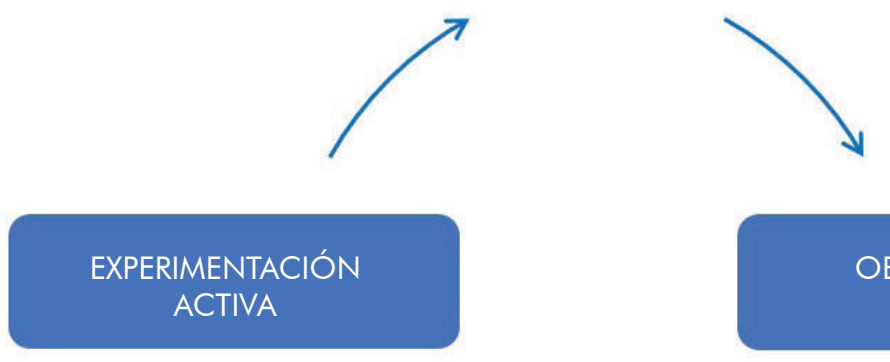

OBSERVACIÓN REFLEXIVA

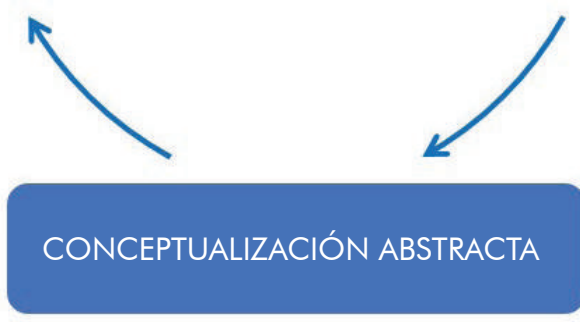

Figura 2: Ciclo de aprendizaje de Kolb. 
Kolb (1984) considera que de la experiencia pasamos a la observación reflexiva que lleva a la ideación, para seguir a una fase de acción o experimentación, ciclo donde se genera el conocimiento y se produce un aprendizaje efectivo al pasar por las cuatro fases del proceso.

Según Gómez (2008) en este proceso aparecen dos ejes transversales:

1. entre experiencia concreta y conceptualización abstracta (percibir sintiendo y pensando), y 2. entre observación reflexiva y experimentación activa (procesamos observando y haciendo).

A partir de ellos se infiere que estos niveles de experiencia se enfocan en cómo es captada la información, cómo es procesada y convertida en significado útil: transitar de la esfera del pensamiento a la acción. Pasar de la teoría a la experiencia, o viceversa, va desarrollando las capacidades, aporta flexibilidad y profundidad para poder transferir y hacer operativos los modelos mentales que se generan en el proceso de aprendizaje, lo cual se verifica en el ciclo de aprendizaje de Kolb:

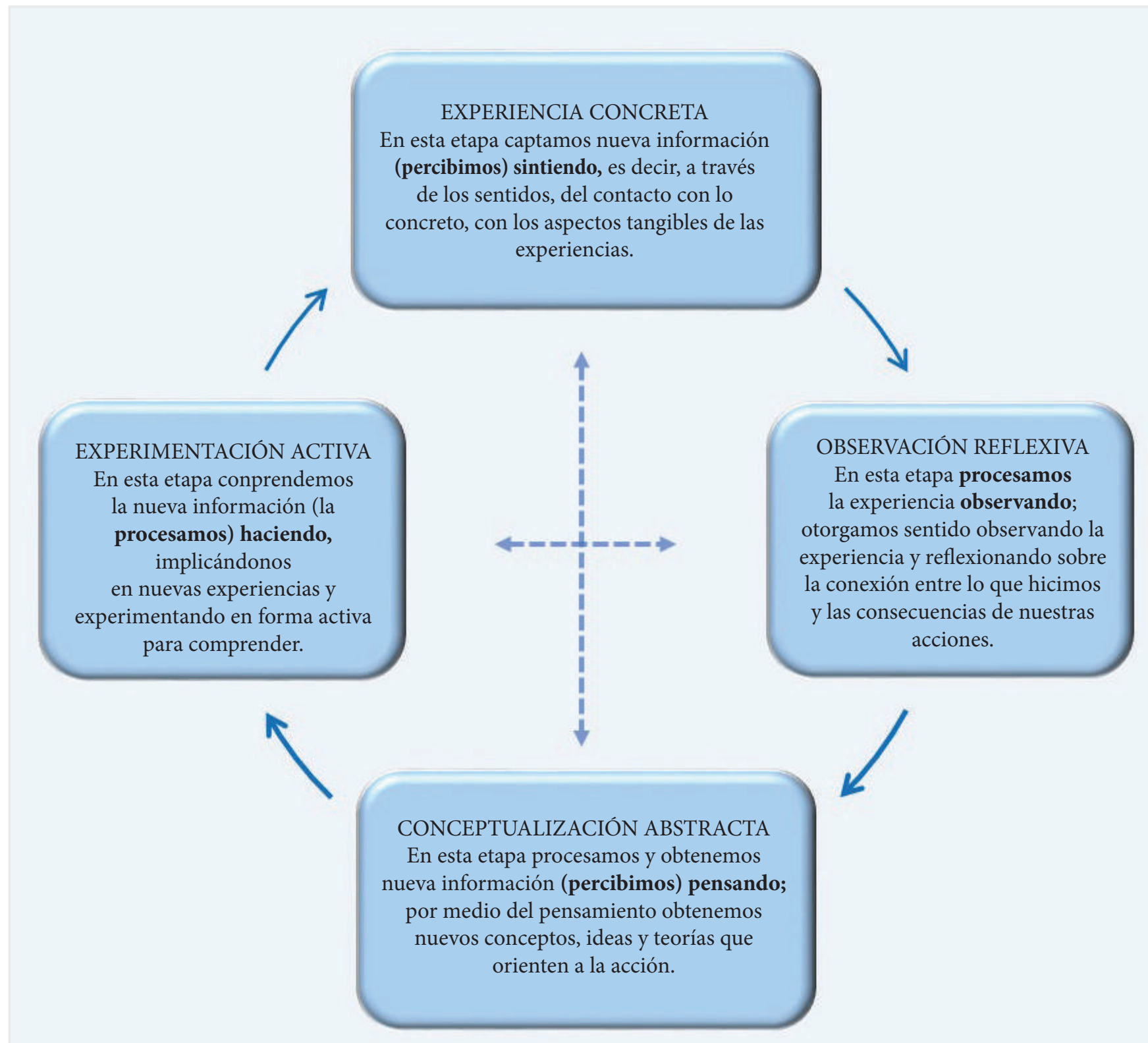

Figura 3: Ciclo de aprendizaje de Kolb ampliado con los ejes de actividades de aprendizaje: percepción y procesamiento. Fuente: Gómez, 2008. 
Por su parte, Brown, Hallet y Stoltz (1994) han demostrado en su estudio que existen preferencias y varios métodos de enseñanza-aprendizaje en estudiantes y profesores de la Arquitectura del Paisaje; los autores muestran que en ese ámbito fueron determinados varios tipos de estudiantes: los sensorios (S), los intuitivos (N), los pensadores ( $T$ ) y los sentidores $(F)$; de estos, los intuitivos (N), los "sentidores intuitivos" (FN) y los pensadores intuitivos (TN) (los cuales componían el $75 \%$ de la muestra) tendían a aprender mejor a través del aprendizaje basado en problemas, coloquios, trabajos de grupo y que preferían los workshops o seminarios a las clases magistrales; al comparar estos resultados con los profesores investigados, existían similitudes entre estos y las respuestas los estudiantes.

Basado en el matiz tanto teórico como práctico de la asignatura de Arquitectura y Paisaje las estrategias que se definan en su desarrollo deben ir aunadas hacia lograr un aprendizaje que comprometa a los estudiantes a tomar posición activa en su propio proceso de aprendizaje, así como en la concreción material del mismo al conectar las condicionantes del medioambiente y los efectos de las intervenciones de la arquitectura en el entorno. Estos elementos pueden aparecer de manera equilibrada y coexistir en el desarrollo de un proyecto de paisaje (ya sea efímero o permanente) por medio del cual los estudiantes en colaboración comprenden, reflexionan y llevan a cabo soluciones a proyectos de diseño de manera consciente en la relación medioambiente-arquitectura-bien común. El bien común es un término que surge en la antigüedad griega de la mano de los filósofos de la época, y para Argandoña (2011) es un concepto asociado a la corriente tomista ${ }^{1}$ (desarrollada por Jacques Maritain) que plantea el bien de las personas en la medida en que forman parte de una comunidad y que por ende está constituida antes que todo por "la virtud, que es y por lo cual de manera positiva y estable, desarrolla a los seres humanos de acuerdo con su naturaleza" (p.2). Aunado a estas ideas se involucra en la indagación el concepto de conciencia medioambiental, definida como la comprensión que se tiene de las acciones de los seres humanos en el entorno (Di Carmine, 2018).

Dichos conceptos se incorporan en el estudio con el objetivo de integrarlos en el aprendizaje a través de proyectos, que para Martí, Heydrich, Rojas y Hernández (2009, p. 13 ) "es un modelo de aprendizaje con el cual los estudiantes trabajan de manera activa, planean, implementan y evalúan proyectos que tienen aplicación en el mundo real más allá del aula de clase", lo que permite que los estudiantes se involucren en problemáticas concretas del contexto y siendo un canal idóneo para que la experiencia del trabajo colaborativo adquiera mayor relevancia, convirtiéndose estos en parte activa del proceso pues aplican lo aprendido en un producto concreto dedicado a satisfacer una necesidad social, mediante lo cual el estudiante "refuerza sus valores y su compromiso con el entorno" (Maldonado, 2008, p. 160).

Para Rojas en Maldonado (2008), uno de los principales beneficios del aprendizaje basado en proyectos es la oportunidad de colaboración para construir conocimiento, mientras a la par van aumentando las habilidades sociales y de comunicación.

\section{Contexto}

En la Escuela de Arquitectura de la Pontificia Universidad Católica Madre y Maestra, Campus Santo Tomás de Aquino (PUCMM-CSTA), la asignatura Arquitectura y Paisaje se encuentra situada en la malla curricular en el año cuatro, período tres, aunque ha sido impartida indistintamente en los tres períodos del año atendiendo a las necesidades de grupos en diversos momentos.

La asignatura se constituye en un medio vinculante y operativo de las asignaturas de diseño a escala de ciudad y de proyectos arquitectónicos de pequeña, media y gran escala. Los cupos en esta asignatura fluctúan entre 20-25 estudiantes, teniendo un promedio de veintiún estudiantes por grupo, lo que precisa que el docente dedique un tiempo considerable al acompañamiento de los proyectos de cada estudiante y lo grupos en el caso del tipo de ejercicio desarrollado.

En esta experiencia se trabajó con tres grupos durante tres periodos académicos, cuyos estudiantes participaron como actores del proceso:

A. El grupo 001, en el periodo académico 1-20162017, con una población de 21 estudiantes, $19 \%$ hombres y $81 \%$ mujeres, finalizando el curso con 20 estudiantes.

B. El grupo 001, en el periodo 1-2017-2018, con 17 estudiantes, $20 \%$ hombres y $80 \%$ mujeres.

C. El grupo 001, en el período 2-2017-2018, con 11 estudiantes, $18 \%$ hombres y $82 \%$ mujeres.

\section{Estrategias de enseñanza-aprendizaje en el desarrollo de proyectos en el paisaje.}

Las estrategias consideradas pertinentes para implementar en esta investigación fueron seleccionadas

\footnotetext{
${ }^{1}$ Relacionada a la corriente filosófica de Santo Tomás de Aquino, que a su vez parte de la filosofía aristotélica. 
a partir de la búsqueda de modelos experienciales de aprendizaje y de los resultados de la investigación de Brown, Hallet y Stoltz (1994). En este caso, y en vista de la situación actual de carencia de espacios públicos y verdes urbanos adaptados para el disfrute de toda la comunidad -desde la visión del bien común-, se inició con la exploración de iniciativas y estrategias que tuvieran en sus objetivos fomentar la conciencia medioambiental y el bien común desde la aproximación del paisaje.

Las estrategias seleccionadas fueron las siguientes:

\section{PARK(ing) Day}

Esta estrategia fue articulada partiendo de las experiencias de la red norteamericana de artistas REBAR que se celebra a nivel mundial desde el año 2005 el tercer viernes de septiembre de cada año. La iniciativa consiste en identificar espacios de parqueos dentro del paisaje urbano y según REBAR (2005) "redefinirlo como un terreno fértil de creatividad social, política y experimentación artística", para re mezclar espacios nicho en el ecosistema urbano y contribuir a la salud y bienestar público.

El grupo de la PUCMM CSTA fue inscrito en la red PARK(ing) Day y se asignaron tres espacios de parqueos a tres grupos en el área del edificio B1, uno frente al edificio de parqueos y dos al interior del parqueo de profesores. En un espacio de $2.5 \mathrm{mts} \times 5$ $\mathrm{mts}$ los estudiantes debían recrear un mini parque y mantenerlo con actividades constantes y animación el día indicado de 9:00 am a 6:00 pm, terminando con el desmantelamiento del mismo y entregando el espacio tal cual les fue inicialmente consignado.

El proyecto de PARK(ing) Day para REBAR (2005), incluye lo absurdo, lo auténtico, lo generoso y un acercamiento táctico con el fin de que el experimento resulte en un punto de quiebre dentro de la estructura urbana, que muestre cómo es posible para cualquiera usar el paisaje urbano como campo de experimentación y juego. Lyndon en Street Plans (2012, p.7) plantea que:

Mejorar la habitabilidad de nuestros pueblos y ciudades comúnmente comienza en la calle, manzana o a escala de construcción. Si bien los esfuerzos a mayor escala tienen su lugar, las mejoras graduales y en pequeña escala se consideran cada vez más como una forma de realizar inversiones más sustanciales.

Esta estrategia fue escogida ya que en lugar constituía el vehículo idóneo para llevar a la realidad un proyecto de paisaje en escala 1:1 (escala natural), pues según
Harrison (2016), es preciso llevar el proyecto del paisaje de la abstracción o representación de la idea del diseño hacia la materialidad que esas ideas quieren crear.

Antes y durante el PARK(ing) Day los estudiantes realizaron una campaña de difusión por las redes sociales Instagram y Facebook, para mantener informados a la comunidad universitaria y motivar la participación en el evento. Al finalizar la actividad las plantas utilizadas fueron donadas a estudiantes y al departamento de Mantenimiento CSTA para su reutilización.

\section{Book de Plantas}

La estrategia del Book de Plantas consistió en realizar un levantamiento de las plantas más utilizadas en el paisaje a nivel local, atendiendo a su origen (endémico o no), familia, marco de siembra, datos morfológicos y mantenimiento. El Book consiste en una estrategia que se convierte en herramienta de consulta donde el diseñador del paisaje tiene a la mano y en un solo golpe de vista las informaciones necesarias para tomar decisiones sobre el uso de las plantas. Esta estrategia fue abordada bajo el modelo de trabajo colaborativo por la cantidad de información que se debía procesar en corto tiempo y sirvió de base para el primer proyecto de diseño de paisaje del curso. Para la realización de esta estrategia no fueron impresos documentos, se trabajó por entero en digital para hacer énfasis en la conciencia medioambiental desde el punto de vista de la economía de recursos.

El Book de plantas es la primera aproximación precisa del estudiante a conocer las características físicas de las plantas, pues para poder desarrollar la conciencia medioambiental es necesario comprender y reconocer primero el elemento principal del trabajo del paisaje: las plantas. Al realizar un acercamiento detallado a este universo de elementos y sus características físicas y de zonas climáticas fue posible que muchos de los estudiantes participantes por primera vez se interesaran por las plantas más allá de lo estético, al reconocer la diversidad e importancia de las mismas en el ecosistema de ciudad.

\section{Guerrilla Gardening}

Una de los proyectos efímeros planteados en el curso fue la Guerrilla Gardening, que, según Lydon (2012), fue acuñada en 1973 por Liz Christy y su grupo Green Guerrilla. Tiene su fundamento en "ajardinar" espacios públicos y privados, preferiblemente sin aviso previo; parte de la idea del cambio o re direccionamiento de espacios (muchas veces inutilizados) y se realiza para levantar conciencia sobre variadas situaciones sociales y medioambientales. 
Los estudiantes fueron convocados a participar en intervenciones individuales o en parejas tomando por sorpresa y por un día espacios del $7 \mathrm{mo}$. piso del edificio B1 de la PUCMM CSTA. Es importante aclarar que el encargo no tenía formato especifico, se dejó fluir la creatividad. En la consigna del ejercicio se solicitó un registro visual de la intervención realizada y un texto de 200 palabras en el cual se explicaran las motivaciones de la idea y el mensaje de conciencia medioambiental que se deseaba comunicar al público, este documento debía colocarse en la tarea correspondiente en la Plataforma Virtual de Aprendizaje Moodle.

\section{StreetScape/Paisaje de Calle}

Este ejercicio constituyó el segundo proyecto del curso en el cual se incrementó la escala de acción hacia la escala de ciudad y fue vinculado al desarrollo de un ciclo de conferencias y Workshop ${ }^{2}$ sobre espacio público y turismo accesible como parte de los requisitos del aprendizaje orientado a proyectos. Las actividades fueron realizadas en conjunto entre las asignaturas de Arquitectura y paisaje ARQ-444-T, Ergonomía y Accesibilidad DIN-213-T de la carrera de Diseño e Interiorismo de la PUCMM y Legislación Turística de la carrera de Turismo de la Universidad Domínico Americano. Este proyecto fue realizado por estudiantes de las tres asignaturas y de las dos universidades en conjunto, con la finalidad de plantear una propuesta de valor para un espacio público de un importante polígono comercial de la ciudad de Santo Domingo carente de un adecuado tratamiento de paisaje y accesibilidad.

En este proyecto se vincularon los conocimientos previos de diseño urbano de los estudiantes de Arquitectura aplicándolos al paisaje; los de ergonomía, de los estudiantes de Diseño e interiorismo, y las normativas legales por parte de los estudiantes de la Universidad Domínico Americano. El día final del proceso fue realizado el Workshop o taller donde se presentaron los resultados y propuestas de los grupos en cada ámbito de acción; al terminar las presentaciones, se realizaron mesas de trabajo compuestas por estudiantes de las tres asignaturas de las dos universidades, redactándose un documento conjunto que sería entregado con posterioridad a las autoridades de la ciudad competentes en el tema de espacio público y turismo.

La variedad de experiencias vividas dio como resultado que cada día los estudiantes esperaran con expectativa qué iba a pasar de novedoso en el curso, lo que supuso el aumento de la motivación, la creatividad, el deseo de emprendimiento y la emoción positiva para el desarrollo de las estrategias.

\section{Metodología}

Las técnicas utilizadas para llevar a cabo este estudio descriptivo aplicado a la asignatura Arquitectura y Paisaje ARQ-444-T durante tres cuatrimestres fueron el cuestionario y el análisis de los contenidos en las anotaciones de los diarios de clases.

\section{Cuestionario para conocer el impacto de las estrategias implementadas}

Finalizada la asignatura y la publicación de las calificaciones correspondientes, en el periodo siguiente 2-2016-2017 se procedió a construir un instrumento de evaluación cualitativa para indagar las opiniones de los grupos de estudiantes que participaron en la experiencia, en el cual se les preguntaba sobre las estrategias utilizadas. El cuestionario fue diseñado en la plataforma Google Forms y enviado un enlace por correo electrónico para acceder al cuestionario. De veinte estudiantes que finalizaron el curso en el 1-20162017, trece respondieron el instrumento, mientras en el grupo 2-2017-2018 de once estudiantes, siete completaron la encuesta.

El cuestionario fue estructurado en cinco apartados:

1. Valoración de la utilidad de los conocimientos adquiridos en la asignatura.

2. Valoración de las estrategias utilizadas en clase.

3. Selección y valoración de la estrategia que más le ayudó a mejorar su nivel de comprensión de la asignatura.

4. Valoración de la utilidad de los conocimientos adquiridos en Arquitectura y Paisaje para la comprensión y consolidación de su conciencia medioambiental.

5. Valoración de la utilidad de la Plataforma Moodle en la organización del curso, acopio de documentos e intercambio de información.

\section{Recogida de Información para conocer el impacto en la conciencia medioambiental}

La recogida de información durante el desarrollo del curso se realizó de manera sistemática, siendo la plataforma Moodle (PVA) y las anotaciones en el diario de planificación $y$ apuntes de clase una fuente importante de datos.

\footnotetext{
2 Un Workshop (voz inglesa) es una reunión donde un grupo de personas trabajan en una actividad específica en un tema o proyecto particular.
} 
Uno de los momentos significativos de reflexión para desarrollar la conciencia medioambiental surgió luego de agotada la parte teórica del día en clase. Se procedió a compartir en la PVA el audiovisual Gretel (12:13 min) y se planteó la discusión sobre la intervención de la arquitectura en la ciudad y lo que ha significado esto para la capa de arbolado. En el periodo académico posterior se presentó un breve corto llamado "Paisaje Marino: Isla de Botellas". Las anotaciones de ambos recursos se presentan a continuación:

Tabla 1: Diario de clases

Anotación del diario de clases

\begin{tabular}{|c|c|c|c|}
\hline \multicolumn{2}{|c|}{$1-2017-2018$} & \multicolumn{2}{|c|}{$2-2017-2018$} \\
\hline 17 octubre 2017 & 17 octubre 2017 & 6 de febrero 2018 & 6 de febrero 2018 \\
\hline 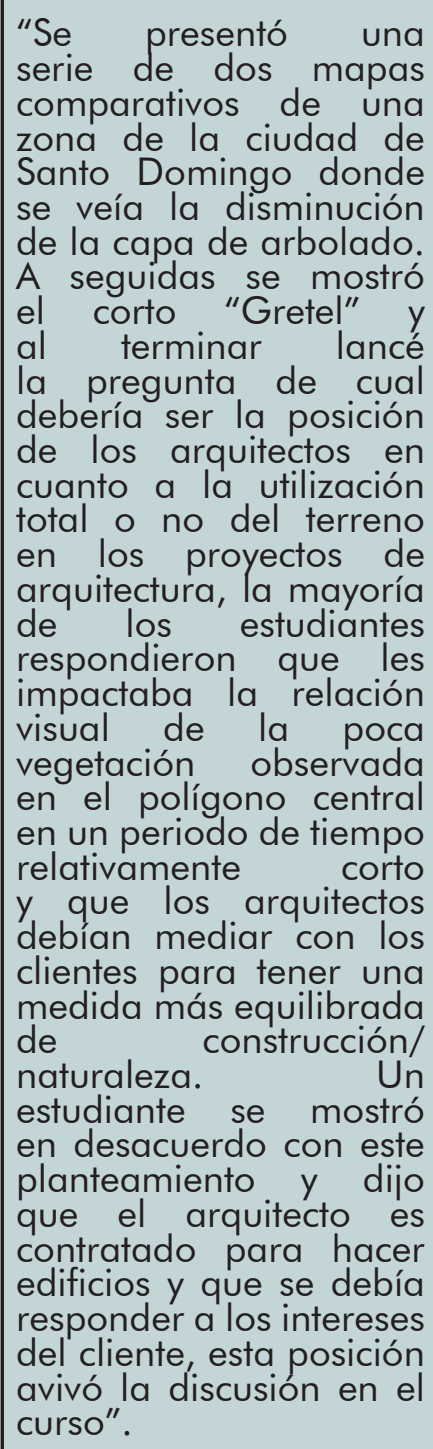 & $\begin{array}{l}\text { "Observé que cuando } \\
\text { a los estudiantes se les } \\
\text { muestran imágenes } \\
\text { comparativas precisas } \\
\text { y con un discurso } \\
\text { claro se da pie a una } \\
\text { reflexión instantánea y } \\
\text { los hace preguntarse } \\
\text { qué se puede hacer } \\
\text { para frenar o aminorar } \\
\text { las consecuencias } \\
\text { de determinadas } \\
\text { acciones en el ámbito } \\
\text { de la arquitectura, que } \\
\text { afectan a la naturaleza y } \\
\text { a la calidad de vida de } \\
\text { sus habitantes". }\end{array}$ & $\begin{array}{l}\text { "Se abrió la discusión } \\
\text { del día sobre los } \\
\text { pareceres del estudio } \\
\text { independiente de los } \\
\text { capítulos del libro Una } \\
\text { breve historia de la } \\
\text { humanidad sobre la } \\
\text { huella del hombre en } \\
\text { el paisaje y se llevó la } \\
\text { discusión hacia otro tipo } \\
\text { de paisaje: el marino. } \\
\text { Fue presentado Isla de } \\
\text { Botellas y las expresiones } \\
\text { de los estudiantes } \\
\text { variaban entre el horror } \\
\text { yla negación. Al finalizar } \\
\text { pedimos reflexionar } \\
\text { sobre el impacto de } \\
\text { nuestras acciones y } \\
\text { consumo en cualquier } \\
\text { tipo de paisaje. El curso } \\
\text { acordó disminuir el uso } \\
\text { de botellas plásticas } \\
\text { desechables, quienes no } \\
\text { tenía una botella de uso } \\
\text { continuo. }\end{array}$ & $\begin{array}{l}\text { "Se dio cuenta de } \\
\text { algo similar a los } \\
\text { sucedido en el curso } \\
\text { del periodo anterior, } \\
\text { el estado de shock al } \\
\text { observar imágenes } \\
\text { inesperadas puso en } \\
\text { evidencia las acciones } \\
\text { del hombre sobre el } \\
\text { paisaje y dio pie a que } \\
\text { os mismos estudiantes } \\
\text { propusieran acciones } \\
\text { para disminuir dicho } \\
\text { impacto, a partir de ser } \\
\text { mas conscientes en sus } \\
\text { decisiones, por ejemplo } \\
\text { con las concernientes al } \\
\text { consumo". }\end{array}$ \\
\hline
\end{tabular}

\section{Resultados}

En esta oportunidad fueron analizados los apartados 2, 3 y 4 del cuestionario.

\section{a. Valoración de las estrategias utilizadas en clase}

Se les pidió a los estudiantes que valoraran independientemente cada estrategia utilizada en clase. Los indicadores utilizados fueron valorar numéricamente del 1 al 5 , siendo uno el menor valor y 5 el de mayor valor. Las mayores valoraciones individuales fueron:

- PARK(ing) day (100\%)

- Guerrilla Gardening (84.6\%) 
- Book de Plantas (76.9\%)

- Proyecto diseño del paisaje $(61.5 \%)$

Esta selección da cuenta del impacto positivo de la realización de estas estrategias, vista bajo las teorias de aprender haciendo (learning by doing).

\section{b. Seleccionar y valorar la estrategia que más le ayudó a mejorar su nivel de comprensión de la asignatura.}

Se construyó una pregunta abierta con posibilidad de respuesta larga, para que los estudiantes desarrollaran sus ideas. Las estrategias a modo general fueron valoradas positivamente por los estudiantes, pero las preferencias estuvieron marcadas como sigue:

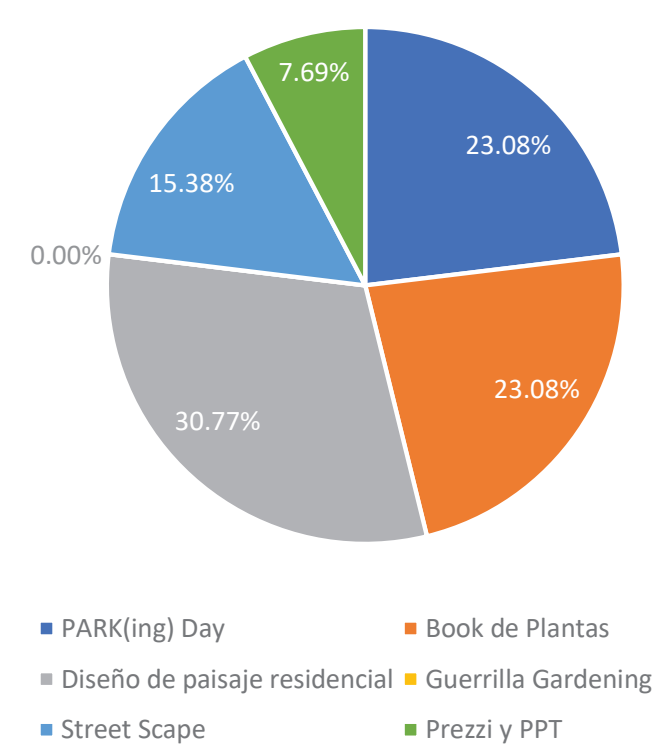

Figura 4: Preferencia de las estrategias implementadas en la asignatura.

En primer lugar, los estudiantes valoraron el Diseño de Paisaje Residencial. Veamos algunos de sus comentarios:

1. "El proyecto residencial, ya que, se puso en práctica (de forma gráfica) lo aprendido en la clase...."

2. "Utilicé los conocimientos previos para algo práctico y cotidiano".

Los estudiantes valoraron en segundo lugar, el PARK(ing) Day, y en tercer lugar, el Book de Plantas. Veamos algunos de sus comentarios al respecto:

1. "Park(ing) Day, ya que pudimos hacer uso de herramientas del paisaje para de alguna forma vincular a los usuarios, observadores y los mismos creadores del proyecto para analizar el valor actual de la naturaleza y su significado en la ciudad".

2. "El parking day, porque nos ayudó o al menos a mí a darme cuenta que las personas desperdician muchos espacios que pueden ayudar al medio ambiente".

3. "El book de plantas porque me permitió acercarme a los tantos tipos de plantas existentes y conocerlas con más detalle para así darles una correcta aplicación".

En tercer lugar, estuvo el StreetScape, en este apartado no explicaron el porqué de la selección.

Resulta interesante observar individualmente el valor de las estrategias, el PARK(ing) obtuvo un 100\% de aceptación, pero al preguntársele por la estrategia que más le ayudó, la mayoría se decanta por seleccionar el Diseño del Paisaje Residencial, estrategia que se enmarca en la tradición de doscientos años del taller de proyectos. Esto ameritaría una investigación más detallada al respecto.

\section{c. Reflexión sobre su comprensión de la conciencia medioambiental.}

En este apartado los estudiantes indican que valoran los conocimientos adquiridos y que desarrollaron la conciencia ambiental en la siguiente proporción: el $77 \%$ dio una alta valoración; un $15 \%$ valoró positivamente y un $8 \%$ valoró medianamente los conocimientos adquiridos para incrementar la conciencia medioambiental.

El aprendizaje de los estudiantes se vio fortalecido a partir de la perspectiva de la implementación de estos proyectos innovadores, al desarrollar actividades que los llevaron a aprender a partir de experiencias concretas, de una participación activa, a reflexionar y a compartir la conceptualización de los fundamentos de paisajes aprendidos. En cuanto al desarrollo de compromiso con el bien común, estos proyectos impactaron en la comunidad universitaria y, para una escala mayor, con el desarrollo de propuestas generadas por equipos multidisciplinarios que impactarán otros ambientes. El impacto de estas estrategias en la conciencia medioambiental y el bien común podrían ser medidos en estudios futuros, monitoreando, por ejemplo, las acciones de un grupo de estudiantes participantes del curso de Arquitectura y Paisaje en las decisiones de ese tenor que tomen en el desarrollo de los proyectos que se les asignen en otras materias relacionadas al diseño del entorno construido y de entornos naturales.

Se presentarán a continuación gráficos comparativos de preguntas clave, las cuales fueron recopiladas mediante encuesta. Se decidió utilizar la recogida de información online para agilizar la recogida y tabulación de datos. 
Las evidencias fueron enfocadas a partir de 6 preguntas de las 13 realizadas en el primer instrumento de recogida de información; a continuación, se muestran las respuestas a las preguntas hechas en ambos momentos de los dos periodos.

Para conocer la respuesta de los estudiantes a la pregunta sobre el grado de información y conocimiento sobre temáticas medioambientales que tenían al inicio y al final del curso, se utilizó una escala de valoración del 1 al 5 , donde el 1 correspondía a un nivel bajo y el 5 a un nivel alto; las respuestas van en el siguiente tenor:

\section{¿Cuál es el grado de información o conocimiento que posee sobre cuestiones relacionadas con el medio ambiente?}

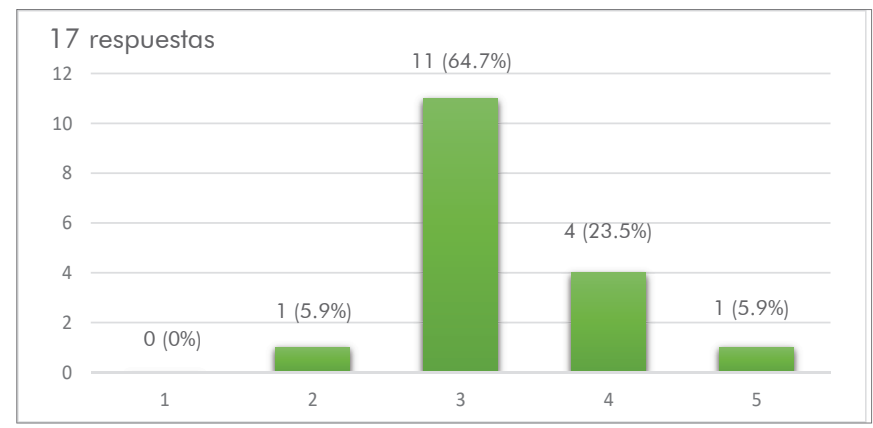

Al inicio curso 1-2017-2018

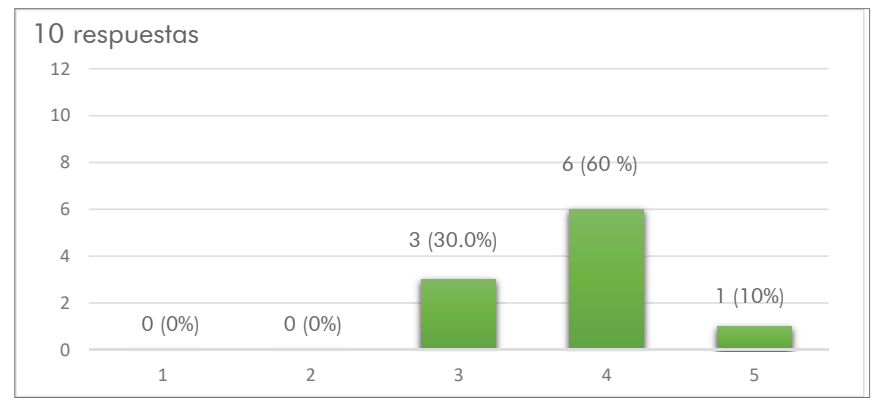

Al finalizar curso 1-2017-2018

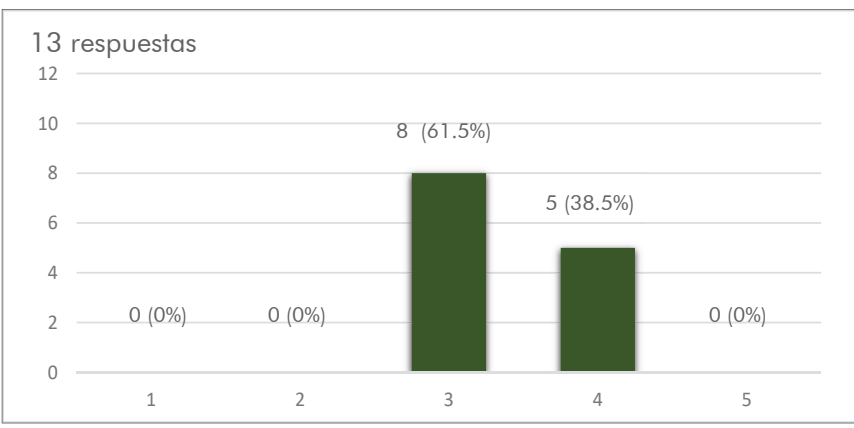

Al inicio curso 2-2017-2018

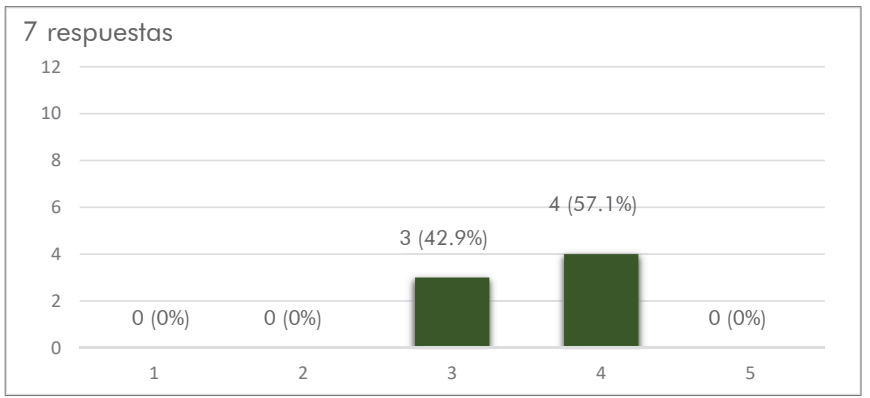

Al finalizar curso 2-2017-2018

Figura 5. Imágenes comparativas de la misma pregunta realizada al inicio y final de periodo en ambos grupos.

Al inquirir si las actividades cotidianas que realizaban repercutían en el medioambiente, las respuestas son similares en ambos grupos, resultando en un ligero incremento de dicha consideración al preguntarles lo mismo al finalizar el curso (en el caso del 1-2017-2018) y obtener una respuesta total afirmativa en el final del 2-2018-2019:

\section{¿Considera que sus actividades cotidianas tienen una influencia significativa en el medioambiente?}

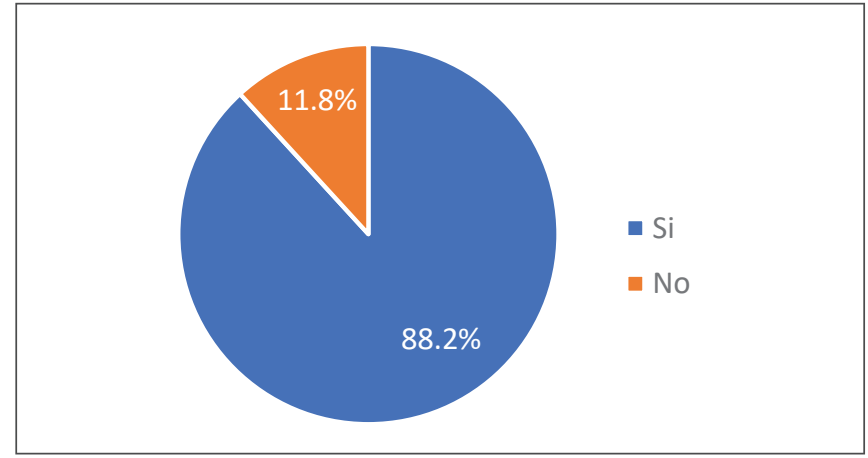

Al inicio curso 1-2017-2018

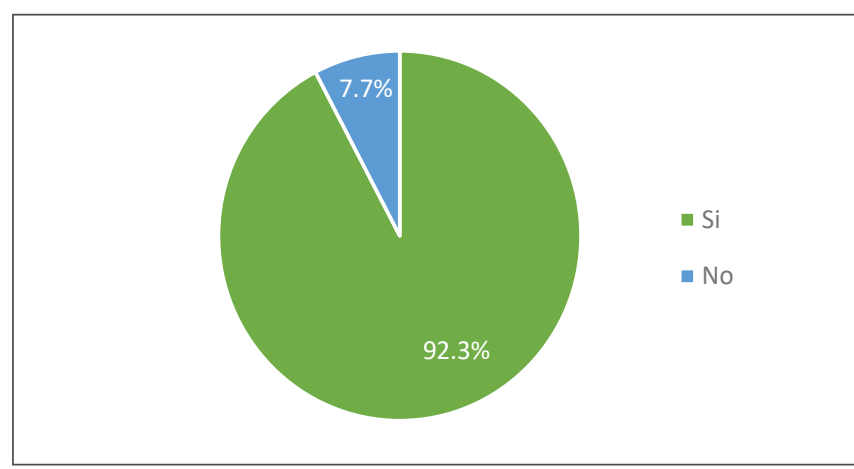

Al inicio curso 2-2017-2018 


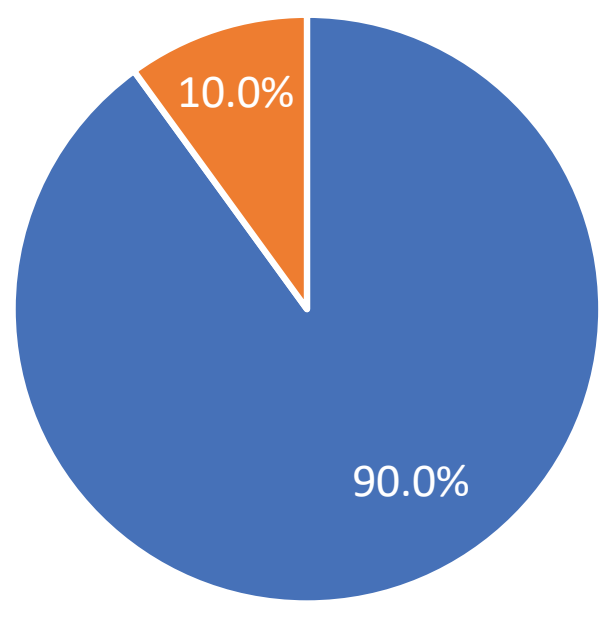

$\because \mathrm{Si}$ No

Al finalizar curso 1-2017-2018

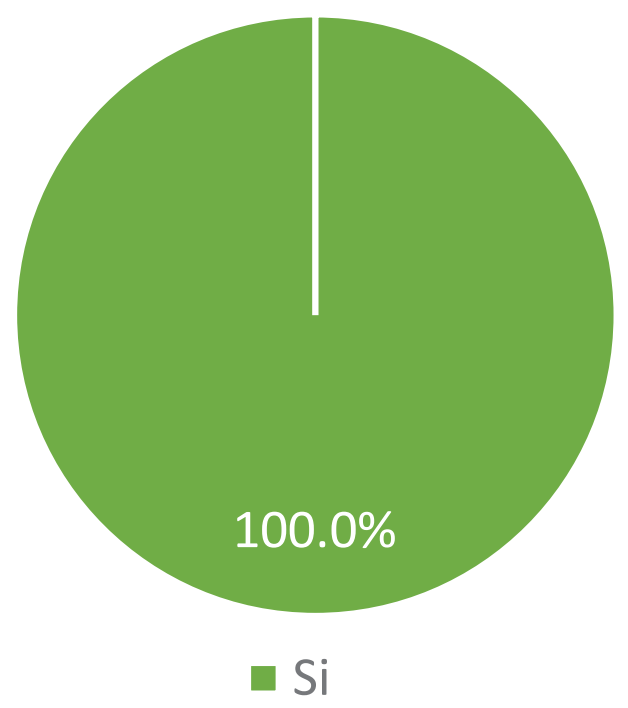

Al finalizar curso 2-2017-2018

Figura 6: Percepción de los estudiantes de la influencia de sus actividades y decisiones diarias en el medioambiente.

Para profundizar esta respuesta, se pidió que explicaran por qué: a continuación, veamos algunos de sus comentarios:

Tabla 2: Declaraciones de los estudiantes sobre el impacto de sus actividades en el medioambiente.

\begin{tabular}{|c|c|l|}
\hline Periodo & No. de cuestionario & \multicolumn{1}{|c|}{ Declaración } \\
\hline Inicio 1-2017-2018 & 15 & $\begin{array}{l}\text { "Mis actividades influyen de manera positiva como también } \\
\text { negativa por el motivo de que utilizo artefactos que afectan al } \\
\text { medio ambiente como por ejemplo: el uso de celulares, aparatos } \\
\text { electrónicos, transporte et. En cuanto al lado positivo hago el } \\
\text { mayor esfuerzo reciclando papeles al momento de hacer una } \\
\text { maqueta, como también ahorrar energía eléctrica en cualquier } \\
\text { lugar que me encuentre, etc.". }\end{array}$ \\
\hline Final 1-2017-2018 & 10 & $\begin{array}{l}\text { "No ha cambiado mi punto de vista sino que lo ha reforzado, } \\
\text { porque antes de esta asignatura, tenía conocimientos sobre los } \\
\text { problemas ambientales que nos están afectando por nuestras } \\
\text { propias acciones, por lo tanto, por mi preocupación en el } \\
\text { tema, busque acciones alternativas para reducir mi impacto } \\
\text { en el mundo. Ahora, a partir de lo aprendido y vivido como } \\
\text { estudiante de arquitectura, mi decisiones estarán más enfocadas } \\
\text { a soluciones que trabajos en la clase, ya que específicamente } \\
\text { con el ejercicio de Green Project, entendí lo delicado que este } \\
\text { proceso de diseño debe ser". }\end{array}$ \\
\hline Inicio 2-2017-2018 & 12 & $\begin{array}{l}\text { "Porque mis costumbres no son exclusivamente mías y cuando } \\
\text { un grupo tiene una misma tendencia tiene un impacto aunque } \\
\text { piense que lo que haga yo solo no importa". }\end{array}$ \\
\hline Final 2-2017-2018 & $\begin{array}{l}\text { "Porque antes pensaba menos en como me comportaba y cómo } \\
\text { estas actividades afectan el medio ambiente, así que he tratado } \\
\text { de disminuirlas lo más posible" }\end{array}$ \\
\hline
\end{tabular}


Cuando se les pregunta si la arquitectura que se construye en actualidad en el contexto local favorecía o no la interacción con la naturaleza, las respuestas van en este orden:

\section{¿Desde su perspectiva, ¿la arquitectura actual -lo que se construye en el contexto local- favorece la interacción con el medioambiente?}

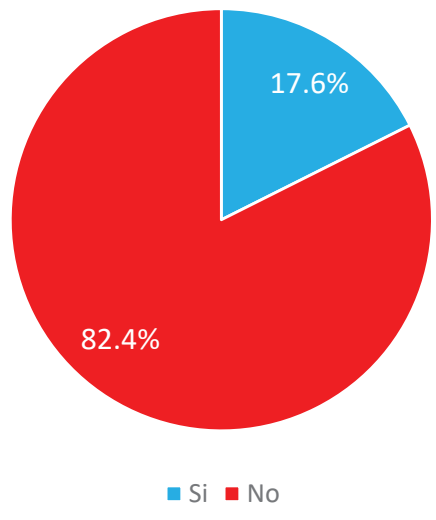

Al inicio curso 1-2017-2018

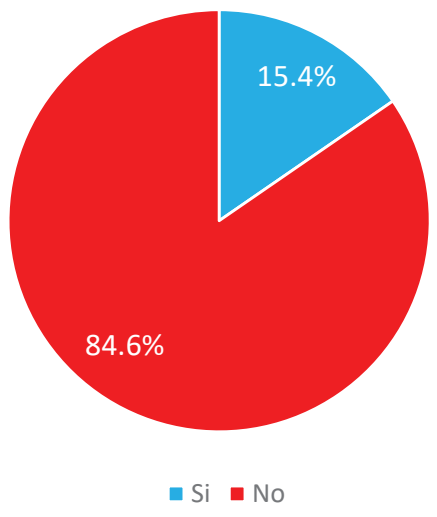

Al finalizar curso 1-2017-2018

Figura 7: Percepción de la influencia de las actividades de los estudiantes en el medioambiente (2017-2018).

Para explicar la respuesta se les pidió elaborar una explicación al respecto en el cuestionario online de inicio de periodo:

Tabla 3: Declaraciones de los estudiantes sobre la arquitectura local y la interacción con el medioambiente.

\begin{tabular}{|c|c|l|}
\hline Periodo & No. de cuestionario & \multicolumn{1}{|c|}{ Declaración } \\
\hline $1-2017-2018$ & 1 & $\begin{array}{l}\text { "Muchas edificaciones actuales son diseñadas solo para cumplir } \\
\text { necesidades propias de sus usuarios dentro del edificio, sin } \\
\text { tomar en cuenta el contexto, las áreas verdes, etc." }\end{array}$ \\
\hline $1-2017-2018$ & 2 & $\begin{array}{l}\text { "En ocasiones sí, los que son conscientes de la gravedad que } \\
\text { está presentando nuestra atmósfera han tratado de ser más } \\
\text { "Green" en sus construcciones". }\end{array}$ \\
\hline $2-2017-2018$ & 3 & $\begin{array}{l}\text { "Porque en nuestro país a veces no es considerado debido a la } \\
\text { falta de conocimientos o costos". }\end{array}$ \\
\hline $2-2017-2018$ & 10 & $\begin{array}{l}\text { "Hoy en día se puede observar cómo cada vez los espacios } \\
\text { verdes disminuyen, utilizan el espacio "libre" para construir y } \\
\text { sacarle dinero, se ha perdido ese vínculo entre la naturaleza, } \\
\text { ese respeto, se destaca como quieren "justificar" o "arreglar" } \\
\text { esta problemática con 3 árboles o "jardines" en isletas, luego } \\
\text { de impactar el entorno. No le están asignando la prioridad que } \\
\text { conlleva consigo el medio ambiente y la naturaleza". }\end{array}$ \\
\hline
\end{tabular}

Al preguntar si los estudiantes estarían dispuestos a participar en actividades pro medioambiente desde la esfera de la arquitectura, contestan lo siguiente: 


\section{¿Participaría en actividades de carácter pro medioambiente tomando la arquitectura como punto de partida?}
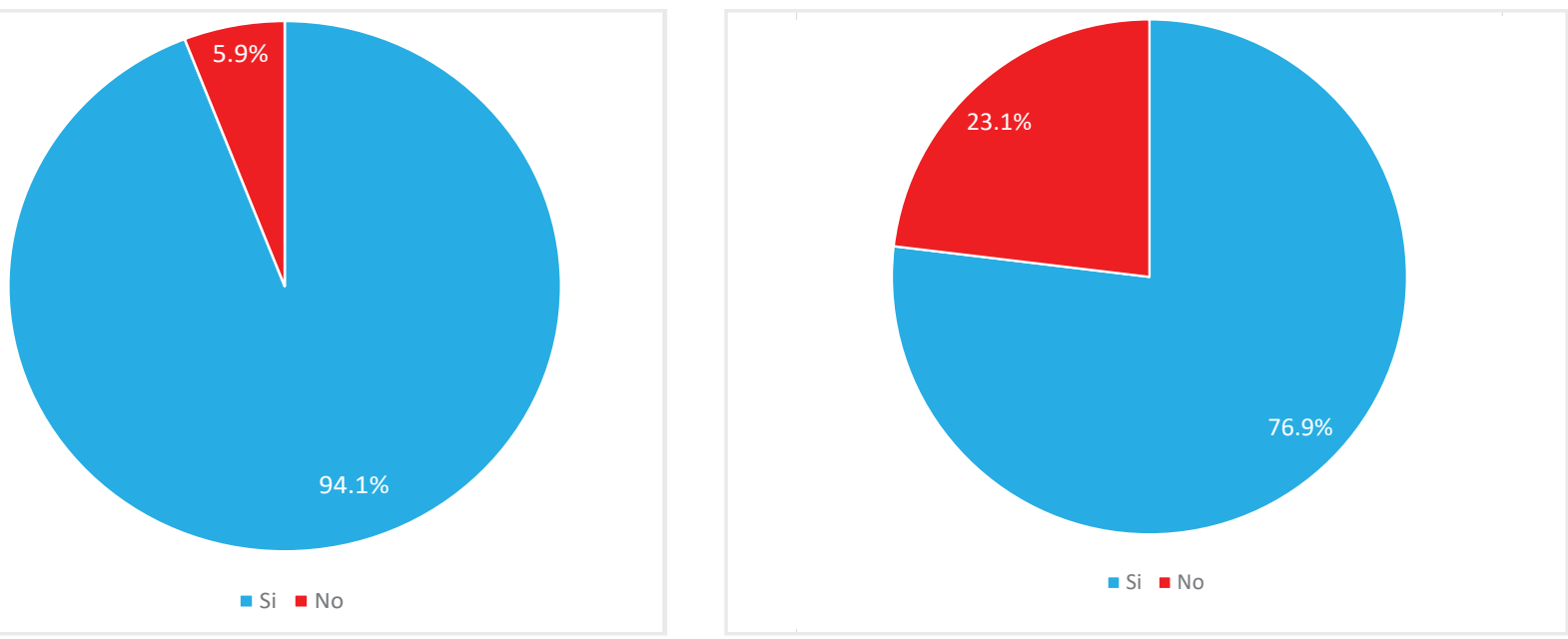

Figura 8: Interés por participar en actividades pro medioambiente.

Quienes contestaron de manera afirmativa, a continuación, seleccionaron en cuáles actividades estarían dispuestos a tomar acción:

\section{¿En cuáles de las siguientes prácticas de responsabilidad medioambiental se comprometería a tomar acción?}

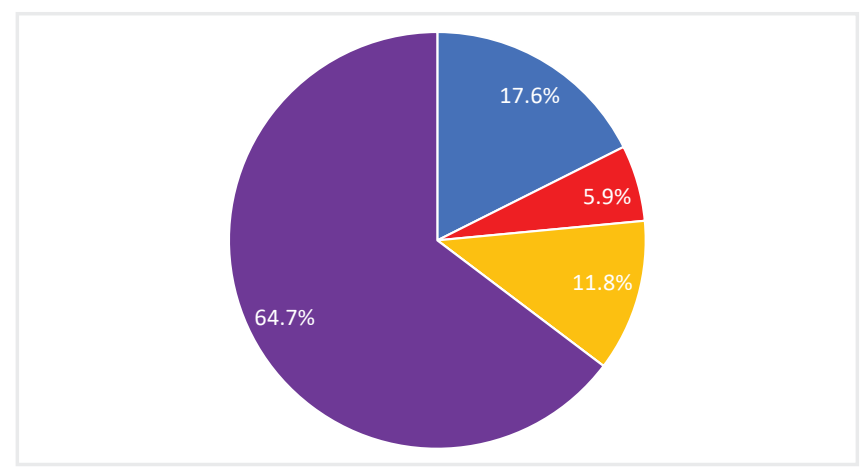

Al inicio curso 1-2017-2018

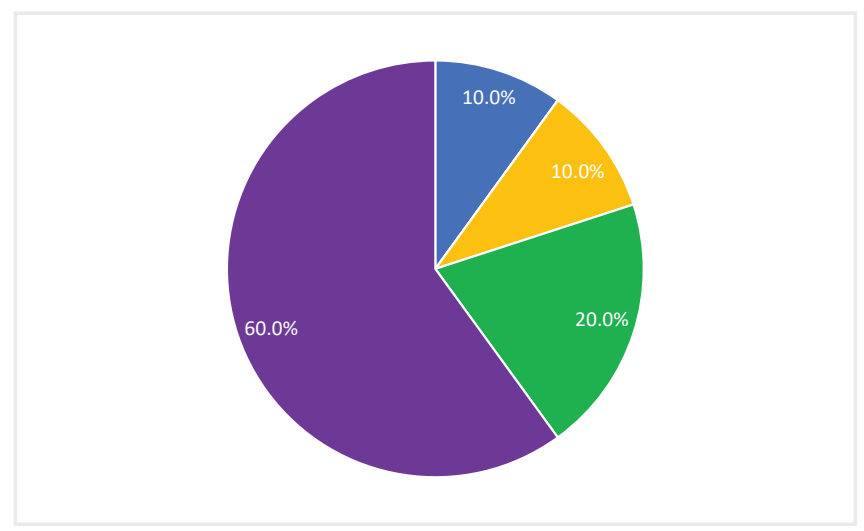

Al finalizar curso 1-2017-2018

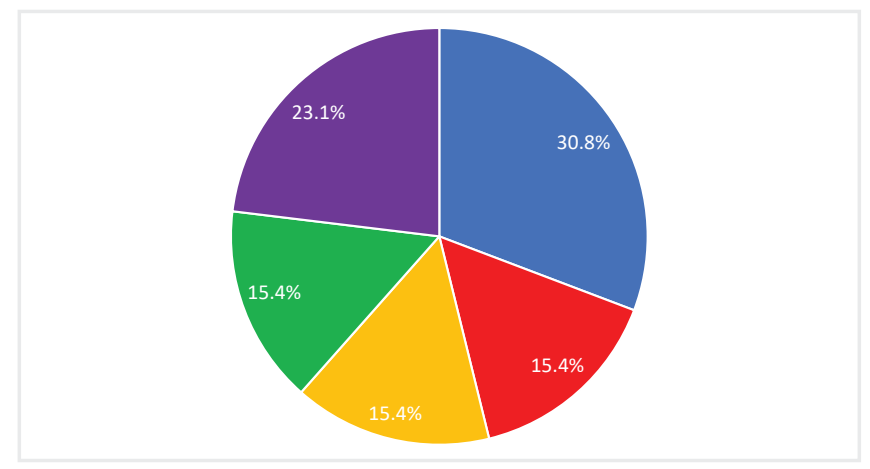

Al inicio curso 2-2017-2018

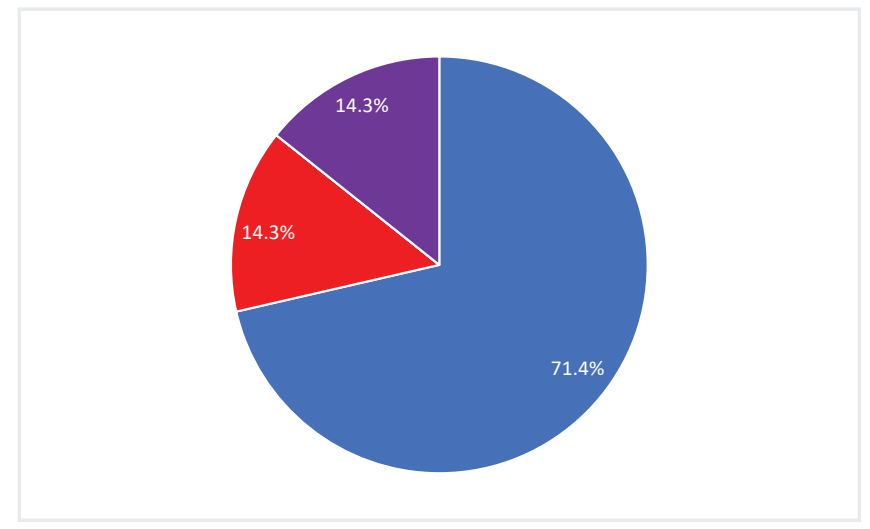

Al finalizar curso 2-2017-2018
En la toma de
Rep
diseño que contemplan reducción del uso de recusos.
Reciclaje.

Uso de transporte colectivo.

Fomentar la creación y uso de espacios verdes.

Figura 9: Acciones que tomarían los estudiantes en pro del medioambiente. 
Es interesante notar que el primer grupo desde el inicio estaba inclinado a la creación de espacios verdes, mientras en el segundo grupo al inicio hay una preponderancia hacia la reducción del uso de recursos y aumenta de manera considerable la noción del impacto de la toma de decisiones en el proceso de diseño que requieran reducción de recursos.

En cuanto al instrumento de recogida de información, hay una diferencia significativa entre el primero utilizado al final del periodo 1-2016-2017 (cuando se comienza a documentar esta indagación por primera vez) con el que se utilizó en el periodo 1-2017-2018 y al finalizar el 2-2017-2018. Este instrumento pasa más allá de evaluar estrategias a hacer preguntas sobre el proceso vivenciado durante el desarrollo de las mismas.

Durante el proceso y para contribuir con la conciencia medioambiental, durante el Park(ing) Day 2017 se dio cuenta en esta ocasión del uso de una mayor cantidad de elementos reciclados y/o alquilados, así como de plantas que los estudiantes traían desde sus propias casas. También, fue muy enriquecedor contar con la participación del grupo de Diseño e Interiorismo y los estudiantes de pasantía de Comunicación Social en el Registro Visual.

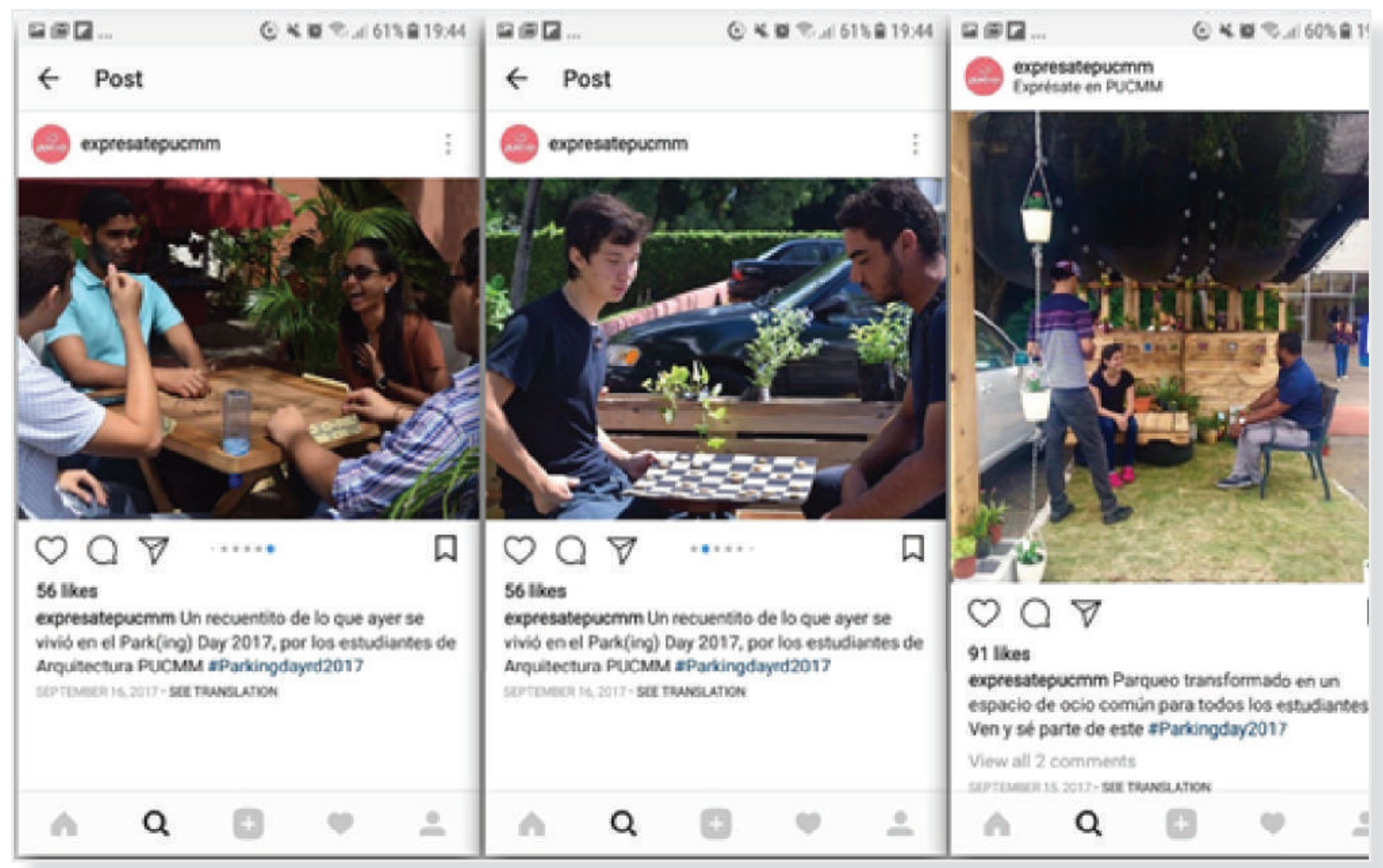

Figura 10: Colaboración de los estudiantes de Expresate PUCMM (Comunicación Social) en la difusión en redes sociales. Fuente: IG Expresate PUCMM (2017).

En cuanto a las preferencias de las personas que usaron los espacios verdes en el Park(ing) Day, se recupera lo siguiente:

Se observó un $50 \%$ del público muy interesado en el espacio y regresaban en cada cambio de clase, esto da cuenta de que, si se crean espacios verdes de calidad, las personas los usarán y los volverán un hábito. 
A su entender, ¿cúal fue la actitud del público en las intervenciones realizadas por su grupo en el Park(ing) day?

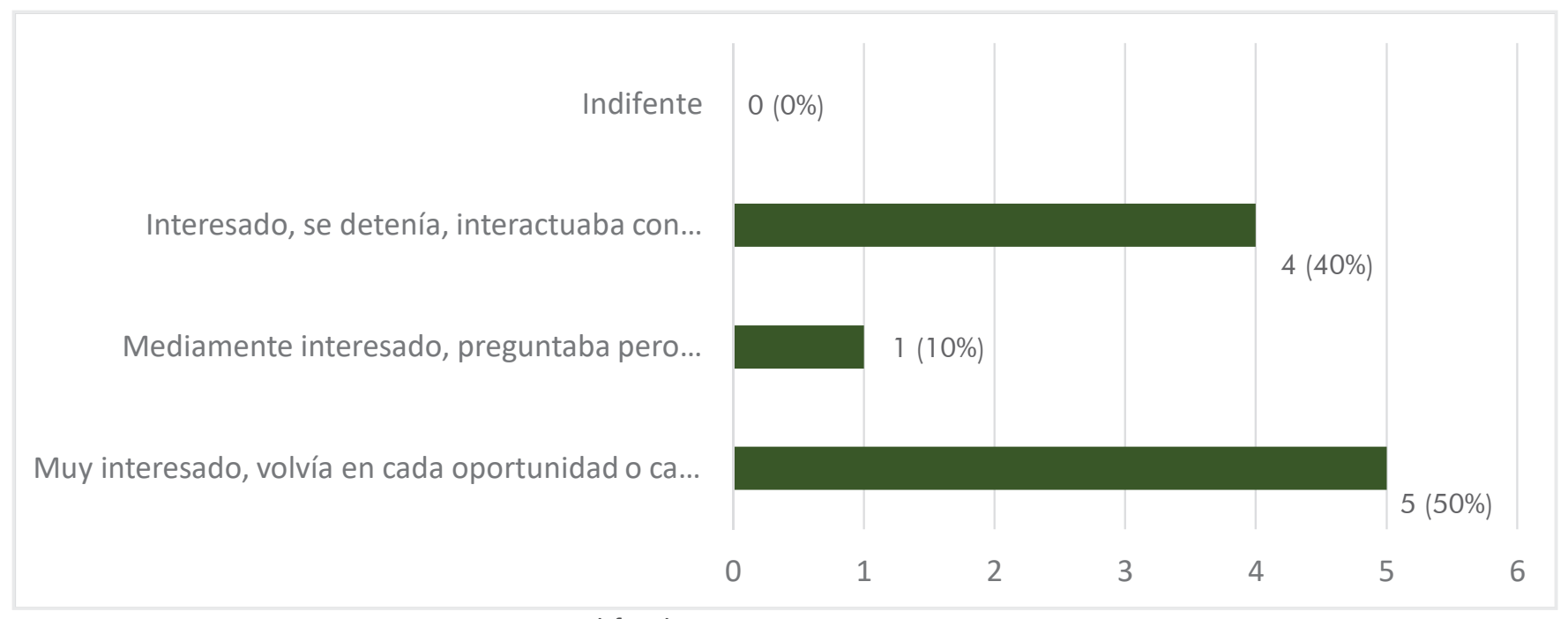

Al finalizar curso 2-2017-2018

Figura 11: Actitud del público en los mini parques.

En el 1-2017-2018 y 2-2017-2018 la preferencia de las estrategias utilizadas reportó lo siguiente:

\section{De las estrategias trabajadas en el curso seleccione la que más le ayudó a mejorar su nivel de comprensión en la asignatura.}

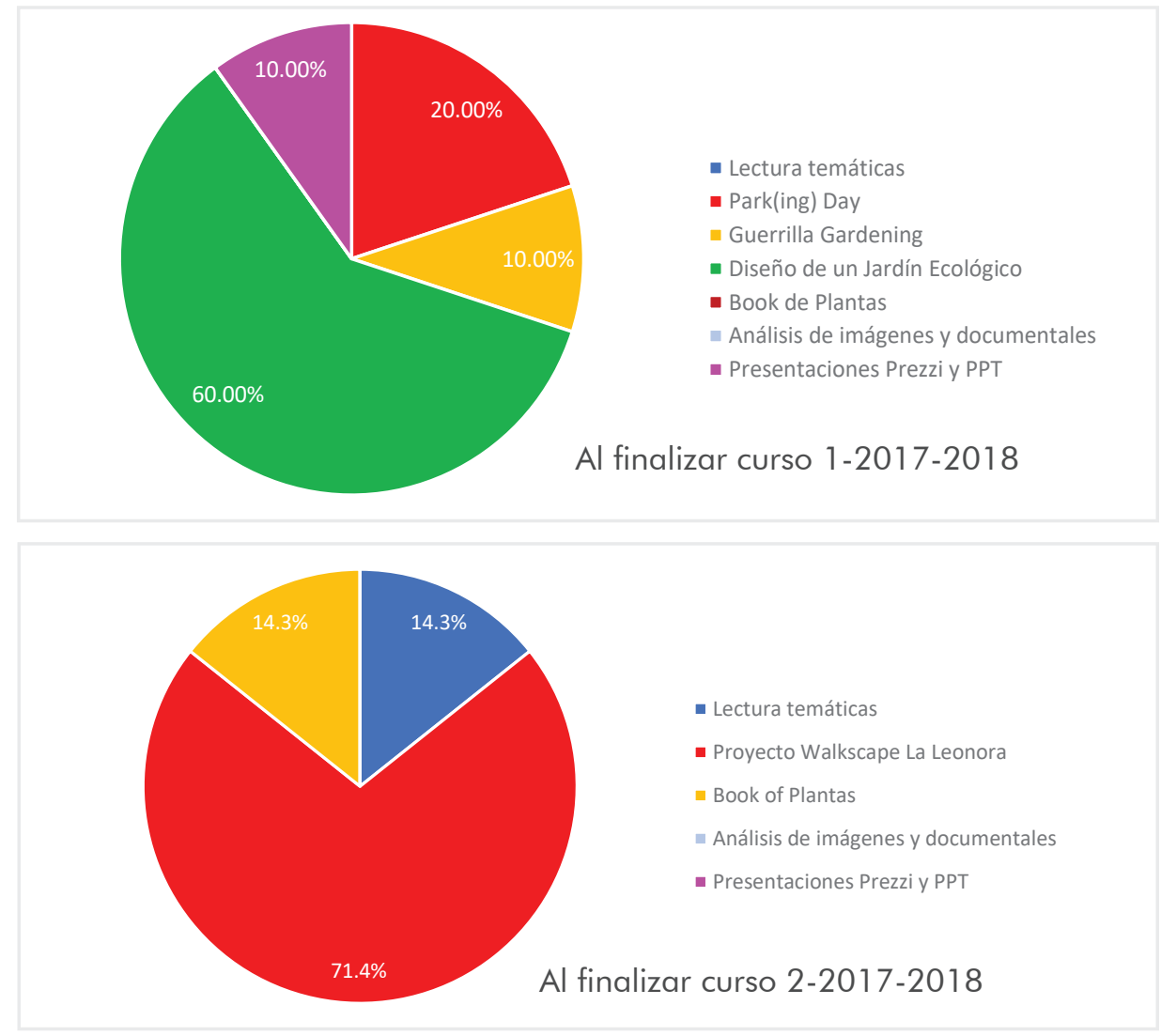

Figura 12: Estrategia mejor valorada durante el curso. 
Al momento esto da cuenta de la consistencia que también se presentó en el curso del 1-2016-2017, pues favorecieron el proyecto tradicional de diseño sobre otras estrategias innovadoras para el aprendizaje.

\section{Conclusiones}

La implementación de estos proyectos innovadores ha traído resultados beneficiosos en varios niveles:

1. En el nivel departamental al contar con realizaciones de proyectos de calidad que dan cuenta del trabajo sistemático y de los aprendizajes de los estudiantes desde perspectivas innovadoras y conectadas a redes de conocimiento globales.

2. El profesorado de la asignatura cuenta con una metodología específica y para la consecución de los objetivos de aprendizaje de la asignatura.

3. Los estudiantes han logrado la transferencia de sus aprendizajes al conectar procesos coherentes en la relación de la ideación del proyecto y su conexión con el medioambiente.

4. El plan de estudios se ve reforzado al tener la asignatura con una mirada enfocada en que el estudiante integre de manera consciente la noción del medioambiente y la relación de este con la calidad del habitar del ser humano en las ciudades, desde el paisaje en el cual se asienta el entorno construido.

El hilo conductor que hilvana esta experiencia de innovación descansa en el conjunto de experiencias desarrolladas por los participantes en el proceso de aprendizaje. El recuento ordenado de las mismas puede ser significativo y de impacto en otras experiencias de innovación, inclusive desde otras disciplinas diferentes a la arquitectura y el paisaje, esto es por la diversidad de actores que pueden interactuar dentro del desarrollo de estrategias de aprendizaje, en la misma u otras escuelas y facultad. A partir de lo vivenciado, se considera que la visión de esta implementación puede ser aprovechada por colegas docentes dentro de diversas áreas disciplinares.

Estas acciones de corta duración posibilitan un cambio de conciencia a largo plazo en los temas envueltos, pues inciden en que los participantes y usuarios se cuestionen sobre la raíz de una problemática y se despierte a los fines de la importancia del bien común al apuntar hacia la necesidad del espacio público verde, haciendo palpable la mejora del mismo al convertir espacios de parqueo en mini parques, a modo de manifiesto medioambiental.
En el desarrollo de estos proyectos a lo largo de tres periodos académicos se plantea que al insertar actividades innovadoras y que reten la capacidad y las habilidades del estudiante, es posible llevar el aprendizaje a un nivel superior. En tanto que la arquitectura es una disciplina proyectual donde se trabaja con el método de proyectos, es importante que estos se mantengan al día para mantener el interés de los estudiantes y, sobre todo, estar conectados con problemáticas reales, con necesidades actuales en las cuales los estudiantes puedan aplicar lo que han aprendido al momento.

Esto puede ser realizado no solamente en las asignaturas proyectuales, también en otros ámbitos, como es el caso de las asignaturas teóricas, se puede dar el paso y acercarse mucho más a lo práctico, esto cambiaría el tipo de atención que el estudiante le da a las mismas.

Uno de los aspectos de mayor valía en la realización de estos proyectos fue lograr redes de colaboración e integración entre diversas carreras, además del apoyo de la Escuela de Comunicación Social y de la Universidad del Domínico Americano, lo cual potenció en gran medida el aprendizaje y la exposición de los proyectos hacia toda la comunidad universitaria. Esta innovación puede seguir el camino hacia la mejora constante si logra integrar en cada oportunidad diferentes actores, llevando siempre como norte la sensibilización y el cambio de actitudes hacia la naturaleza, que es a fin de cuentas lo que da sostén a toda la vida en el planeta, sin olvidar que todo lo que hagamos por ella derivará en el bien común.

\section{Referencias}

Argandoña, A. (2011) The common good. (Working paper 937). Consultado en abril 2018. Disponible en https://www.iese.edu/research/pdfs/DI-0937-E. pdf

Brown, R. D., Hallett, M. E., y Stoltz, R. R. (1994). Student learning styles in landscape architecture education. Landscape and Urban Planning, 30(3), 151 . 157.

Díaz-Barriga, F., y Hernández, G. (1999). Estrategias docentes para un aprendizaje significativo. Una interpretación constructivista. 2da edic. McGraw Hill: México.

Di Carmine, F. (2018). La Biofilia y los beneficios de interactuar con la naturaleza. Charla online de la Fundación Bosque Sagrado disponible en https://www. facebook.com/fundacionbosquesagradodominicana/ videos/1333245600110014/ ? comment id=1333346770099897ynotif_id=1525012079041 299ynotif_t=video_replyyref=notif 
Filor, S. (1994). The nature of landscape design and design process. Landscape And Urban Planning, 30(3), 121-129.

Gazvoda, D. (2002). Characteristics of modern landscape architecture and its education. Landscape And Urban Planning, 60, 117-133.

Gómez, J. (2008). El aprendizaje experiencial. Facultad de Psicología, Universidad de Buenos Aires. Consultado en abril 2018. http://www. ecominga.uqam.ca/PDF/BIBLIOGRAPHIE/GUIDE_ LECTURE_5/1/3.Gomez_Pawelek.pdf

Harrison, F. (2016). Garden as 1:1: Between Paper Thinking and Earth Moving in Landscape Architectural Learning. Landscape Review, 16(2), 26-42.

Kolb, D. (1984). Experiential Learning. Englewood Cliffs, New Jersey: Prentice Hall.

Laurie, M. (1983). Introducción a la Arquitectura del paisaje. Barcelona: Gustavo Gili.

Lydon, M. (2012). Tactical Urbanism 2. Short termaction|long-term change (1ra ed., p. 16). Miami: Street Plans.

Maldonado, M. (2008). Aprendizaje basado en proyectos colaborativos. Una experiencia en educación superior. Laurus, 14 (28), 158-180. Consultado el 16 de abril 2018. Disponible en http://www. redalyc.org/pdf/761/76111716009.pdf

Martí, J.; Heydrich, M.; Rojas, M. y Hernández, A. (2009). Aprendizaje basado en proyectos: Una experiencia de innovación docente. REVISTA Universidad EAFIT, 46 (158), 11-21. Consultado en 16 abril 2018. Disponible en http://publicaciones. eafit.edu.co/index.php/revista-universidad-eafit/ article/view/743/655.

Martínez de Pisón, E. (2012). Sobre la idea y la enseñanza del paisaje. Nimbus, (29- 30), 373-380.

Medina, O. (2011). Del pensamiento a la forma: Estrategias de enseñanza que fomenten la integración del conocimiento en la asignatura Teoría de la Arquitectura I (Postgrado). Pontificia Universidad Católica Madre y Maestra.

Rebar. The PARK(ing) Day Manifesto. Self-Generated Urbanism and Temporary Tactics for Improving the Public Realm. (2011). San Francisco, California.
Schön, D. (1985). The Design Studio: An exploration of its traditions and potentials, London: RIBA.

Zabalza, M. A. (2003). La enseñanza universitaria: el escenario y sus protagonistas. Narcea, 2001. 